\title{
Selective Extraction of Light Lanthanides(III) by $N, N$-di(2-ethylhexyl)- diglycolamic Acid: A Comparative Study with N,N-dimethyl-diglycolamic Acid as A Chelator in Aqueous Solutions
}

Sherif M. Ibrahim,,$^{\dagger}$ \& Yan Zhang, * ${ }^{\dagger}$ Yun Xue, ${ }^{\dagger}$ Suliang Yang, ${ }^{\dagger}$ Fuqiu Ma, ${ }^{\dagger}$ Yang Gao, ${ }^{\dagger}$ Yu Zhou ${ }^{\dagger}$ and Guoxin Tian*广t

${ }^{\dagger}$ College of Nuclear Science and Technology, Harbin Engineering University, Harbin, Heilongjiang, 150001, China.

Department of Radiochemistry, China Institute of Atomic Energy, Beijing, 102413, China.

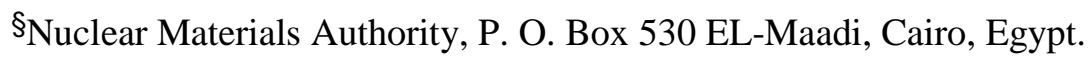




\section{Section A: Dimerization Constant of HDEHDGA, (HA) in kerosene}

\section{Experiments for dimerization constant determination:}

In sample preparation and measurement process, the experiments were carried out in an oxygenfree environment to avoid the influence of carbon dioxide in the air on the $\mathrm{pH}$ value of the aqueous phase. First, HDEHDGA stock solution and the solvent (kerosene) were preequilibrated with boiled $10 \mathrm{mM} \mathrm{NaCl}$ for three times. Then, 0.001, 0.002, 0.003, 0.01, 0.03, 0.05, 0.07, 0.10 M HDEHDGA in kerosene were contacted with same volume of $10 \mathrm{mM} \mathrm{NaCl}$ at $25^{\circ} \mathrm{C}$ for $0.5 \mathrm{~h}$. After centrifugation the $\mathrm{pH}$ values of the aqueous phases were measured using a $\mathrm{pH}$ meter (ROSS 8102B electrode, pH calibration using Fluke 4.00 and 7.00 buffer solutions) at $25^{\circ} \mathrm{C}$. Three parallel sets of samples were prepared and each sample was measured three times.

\subsection{Calculation and formula deduction:}

The dimerization equation is as following:

$H A_{\text {org. }}+H A_{\text {org. }} \stackrel{K_{2}}{\leftrightarrow} \mathrm{HA} \cdot \mathrm{HA}_{\text {org }}$

The distribution of HDEHDGA between the organic and the aqueous phases and the deprotonation of HDEHDGA in the equilibrated aqueous solution are illustrated as in Scheme S1:

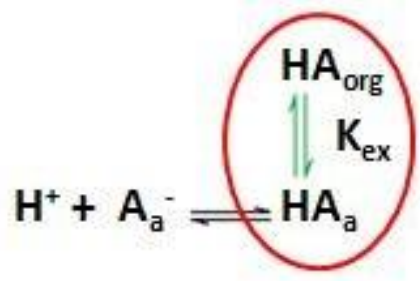

Scheme S1 of HDEHDGA carboxylic acid (HA) dimerization and dissociation in extraction system.

$K_{e x}=\frac{[H A]_{a}}{[H A]_{\text {org }}}$

$\mathrm{K}_{\mathrm{ex}}$ is the distribution coefficient of HA between the aqueous and organic phases (i.e., the ratio of the concentration of a substance in two insoluble solvents at equilibrium, which is a constant depending on temperature.)

In a separate experiment, appropriate amounts of HDEHDGA were directly dissolved in $10 \mathrm{mM}$ $\mathrm{NaCl}$ at $25{ }^{\circ} \mathrm{C}$ ). The dissociation constant (protonation constant), $\mathrm{K}_{\mathrm{a}}$ was calculated to be $9.53 \times 10^{-5}$ using following equation:

$K_{a}=\frac{\left[A^{-}\right]_{a} \times\left[H^{+}\right]_{a}}{[H A]_{a}}=\frac{\left[H^{+}\right]_{a}^{2}}{[H A]_{a}}$ 
Apparent dissociation constant is defined as:

$K_{a}^{*}=K_{a} x K_{e x}=\frac{\left[A^{-}\right]_{a} \times\left[H^{+}\right]_{a}}{[H A]_{a}} x \frac{[H A]_{a}}{[H A]_{\text {org }}}$

The dimerization constant is defined as:

$K_{2}=\frac{[\mathrm{HA} \cdot \mathrm{HA}]_{\text {org }}}{[\mathrm{HA}]_{\text {org }}^{2}}$

The following equations can be deduced from the speciation of HA in the two phase's system:

$[H A]_{\text {total }}=[H A]_{\text {org. }}+2[\mathrm{HA} \bullet \mathrm{HA}]_{\text {org. }}+[H A]_{a}+\left[A^{-}\right]_{a}$

$[\mathrm{HA} \bullet \mathrm{HA}]_{\text {org. }}=\frac{1}{2}\left([H A]_{\text {total }}-[H A]_{\text {org. }}-\left[A^{-}\right]_{a}\right)$

$\left[A^{-}\right]_{a}=\left[H^{+}\right]_{a}$

$[H A \bullet H A]_{\text {org. }}=\frac{1}{2}\left([H A]_{\text {total }}-[H A]_{\text {org. }}-\left[H^{+}\right]_{a}\right)$

$[H A \cdot H A]_{\text {org. }}=K_{2} \bullet[H A]_{\text {org }}^{2}$.

$[H A]_{a}=\frac{\left[H^{+}\right]^{2}}{K_{a}}$

$[H A]_{\text {org. }}=\frac{\left[H^{+}\right]_{a}^{2}}{K_{a}^{*}}$

$[H A]_{\text {total }}=[H A]_{\text {org. }}+2 K_{2} \cdot[H A]_{\text {org. }}^{2}+\frac{\left[H^{+}\right]^{2} a}{K_{a}}+\left[H^{+}\right]_{a}$

$K_{2}=\frac{[H A]_{\text {total }}-[H A]_{\text {org. }}-\left[H^{+}\right]_{a}-\frac{\left[H^{+}\right]^{2} a}{K_{a}}}{2[H A]_{\text {org }}^{2}}$

Where:

$[H A]_{\text {total }}$ : is the total concentration of HA added to the system before extraction. $\left[A^{-}\right]_{a}$ : The anion $\mathrm{A}^{-}$concentration in aqueous phase after extraction equilibrium. $\left[\mathrm{H}^{+}\right]_{a}$ : is $\mathrm{H}^{+}$concentration in aqueous phase after extraction equilibrium.

$[H A]_{a}$ : HA concentration in aqueous phase after extraction equilibrium.

$[H A]_{\text {org. }}$ : HA concentration in organic phase after extraction equilibrium.

$[\mathrm{HA} \bullet \mathrm{HA}]_{\text {Org }}: \mathrm{HA} \bullet \mathrm{HA}$ concentration in organic phase after extraction equilibrium. In the aqueous solutions, $\left[A^{-}\right]_{a}=\left[H^{+}\right]_{a}$, both can be determined by $\mathrm{pH}$ meter. 


\section{Iteration method:}

At the starting point, the concentration of HA (HDEHDGA) in organic phase is very low (initial $0.001 \mathrm{M}$ ), so we assume that ligand molecules dissociate to exist as monomer, HA. Then Ka* can be obtained. When the concentration of HA in organic phase is further increased, part of HA in the organic phase forms dimer.

By substituting $[H A]_{\text {org. }}=\frac{\left[\mathrm{H}^{+}\right]^{2} a}{K_{a}^{*}}$ into equation (14), then the calculated $\mathrm{K}_{2}$ could be applied for the $K_{a}^{*}$ correction of the sample at very low initial concentration $(0.001 \mathrm{M})$. For $\mathrm{K}_{2}$ calculation in $0.01,0.03,0.05,0.07$, and $0.1 \mathrm{~mol} / \mathrm{L}$, the iteration correction is repeated until the modified $\mathrm{Ka}^{*}$ and $\mathrm{K}_{2}$ no longer change.

Table.S1 the $\mathrm{pH}$ values as a function of ligand concentration.

\begin{tabular}{cc}
\hline HDEHDGA/M & $\mathbf{p H}$ \\
\hline 0.00097 & 4.676 \\
0.00194 & 4.559 \\
0.00291 & 4.478 \\
0.00388 & 4.419 \\
0.00582 & 4.334 \\
0.00776 & 4.289 \\
0.0097 & 4.261 \\
\hline
\end{tabular}




\section{Section B: Stripping Nd(III) and reusability of HDEHDGA}

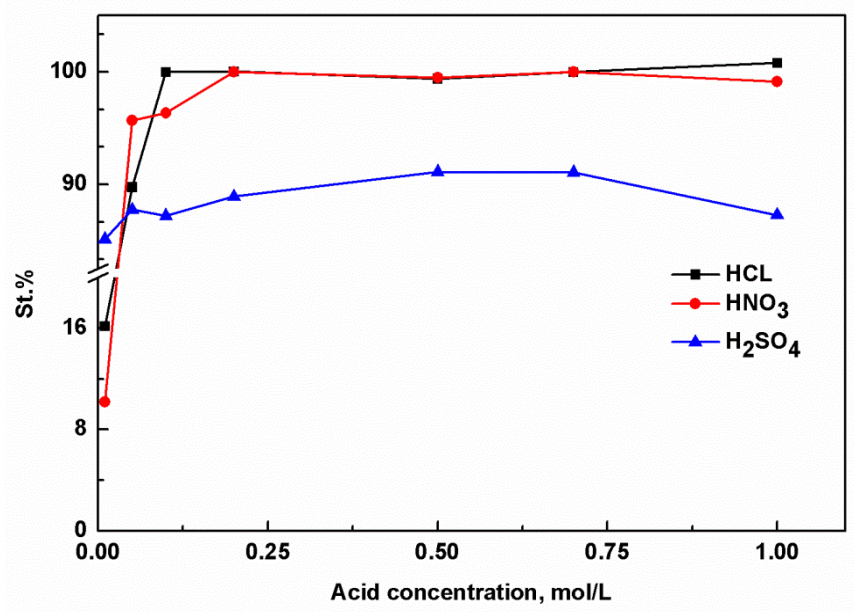

Figure S1 Stripping Nd(III) from the loaded organic phase using different mineral acids, $\left[\mathrm{Nd}^{3+}\right]=0.02$ $\mathrm{mM}$ in the organic phase.

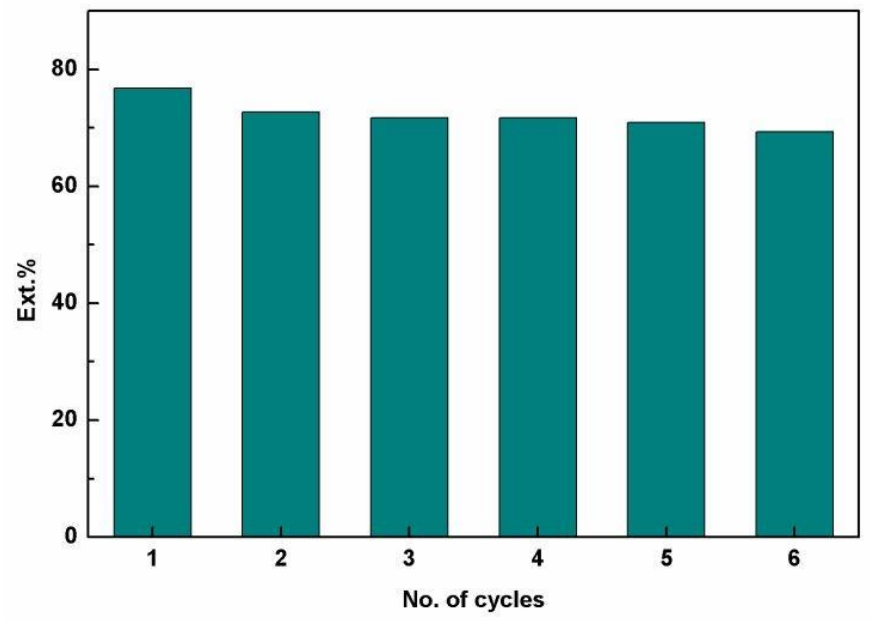

Figure S2 Reusability of the extractant, $\left[\right.$ HDEHDGA] $=0.01 \mathrm{M},\left[\mathrm{Nd}^{3+}\right]=0.027 \mathrm{mM}, \mathrm{pH}=2$, in $1 \mathrm{M}$ $\mathrm{NaCl},[\mathrm{HCl}]$ stripping $=1 \mathrm{M}$ 